\title{
Reseña de Gaspar Aguilar, La comedia segunda de Los agravios perdonados, ed. C. George Peale, Santa Barbara, University of California, Publications of eHumanista, 2016, 128 pp., edición digital
}

\section{Ariel Núñez Sepúlveda}

Universidad de Chile

CHILE

ariel.nunez@ug.uchile.cl

[Hipogrifo, (issn: 2328-1308), 5.2, 2017, pp. 601-603]

Recibido: 24-03-2017 / Aceptado: 24-04-2017

DOI: http://dx.doi.org/10.13035/H.2017.05.02.36

La edición de La comedia segunda de Los agravios perdonados realizada por C. George Peale posee un doble mérito: en primer lugar, pone a disposición del público lector de teatro áureo un texto sumamente confiable y provechoso de un dramaturgo - Gaspar Aguilar - del cual aún queda mucho por investigar, por lo que la presente publicación puede servir, sin duda, como un sólido punto de partida para futuros estudios. Y, en segundo lugar, la edición de Peale se publica en formato electrónico, disponible en acceso abierto a través de la revista eHumanista', facilitando así la divulgación del autor y la obra en un momento en donde la digitalización de la labor filológica fomenta nuevas posibilidades de aproximación a los fenómenos culturales del Siglo de Oro.

La comedia segunda de Los agravios perdonados es una comedia palatina que expone los enredos cortesanos de amor, honor y celos entre las familias reales de Inglaterra, Escocia y Francia. El centro de la acción dramática lo ocupa el romance entre la infanta escocesa, Leonora, y el infante inglés, Fabio. Como indica el editor, esta sería la segunda parte de una comedia desconocida atribuida a Luis Vélez de Guevara, lo cual se deduce a partir de varios indicios: los versos finales de la pieza, una décima que aparece como apostilla en el manuscrito del texto y el propio título de la obra. A pesar de que esta continuación de la pieza perdida de Vélez de Guevara está atribuida al mismo dramaturgo ecijano, Peale, en el conciso y esclarecedor estudio que antecede al texto literario, rechaza aquella atribución y postula como autor de esta comedia segunda al valenciano Gaspar Aguilar (1561-1623), poeta,

1. La edición puede descargarse en el siguiente enlace web: <http://www.ehumanista.ucsb.edu/publications/monographs> [23/10/2017]. 
cronista y panegirista aurisecular. En efecto, uno de los objetivos de esta edición consiste precisamente en realizar una reivindicación historiográfica que ilumine el corpus de estos dos ingenios - Vélez y Aguilar-.

Tras la presentación del libro y un útil resumen de la enrevesada trama, Peale procede a analizar el problema de la autoría del texto a través de distintos aspectos del mismo que, en su conjunto, apuntan a la conclusión de que la pieza nació de la pluma de Aguilar y no de Vélez. Primeramente, se encuentra la décima que aparece al final del manuscrito y que dice lo siguiente:

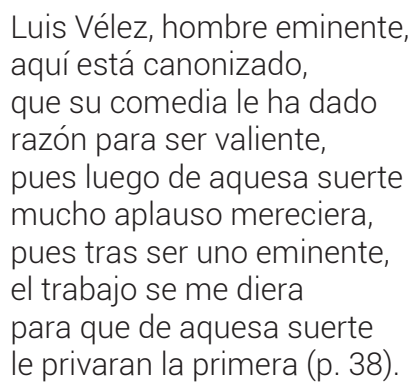

Estos versos, aunque se ubican al término del testimonio de la comedia, funcionan más bien como una loa. Y justamente las obras de Aguilar suelen estar introducidas por una loa de mínima extensión, como la recién citada, lo que no ocurre por lo general en los títulos de Vélez de Guevara, donde escasean los paratextos dramáticos. Por este motivo, Peale acertadamente dispone estos versos precediendo a la obra. Otros elementos compositivos distancian a La comedia segunda de Los agravios perdonados del canon veleciano; así, «la vaga situación dramática y la imprecisión del lugar en la escena inicial» (p. 8) divergen con respecto a las aperturas teatrales del ecijano, marcadas, al contrario, por su claridad y economía. La duplicación onomástica de los personajes es otro factor que aleja a la comedia de la dramaturgia de Vélez: en la obra existen dos personajes de nombre Fabio, homonimia confusa ausente en la configuración de los elencos de personajes del astigitano. Un tercer elemento de la composición dramática que acerca la obra a la escritura teatral de Aguilar es el inicio estruendoso articulado en torno a locuciones performativas y a la utilización de una suntuosa escenografía, que Peale analiza en extenso comparándola con otros comienzos de comedia del corpus de Aguilar. Finalmente, un último componente literario que descarta la atribución a Vélez lo constituye la presencia de agresiones físicas hacia personajes femeninos en el desarrollo de la acción -en esta segunda comedia hay dos-. Tal desvío del decoro no se aprecia en el «habitus dramático» de Vélez de Guevara, quien más bien «escenifica riñas cómicas y dramáticas, atracos, duelos de honor, defenestraciones, batallas y cruentas escenas de suplicio» (p. 15).

Peale no solo aborda las formas de construcción de la trama y los personajes, sino que avanza hacia el estudio comparativo de la versificación entre la praxis de los dos poetas. Mientras que en La comedia segunda de Los agravios perdonados el uso métrico y estrófico más abundante es la quintilla -que alcanza la altísima 
suma del 95\%-, en las piezas velecianas el uso de aquella estrofa es «relativamente limitado» (p. 17), como anota Peale. Este perfil métrico de la obra editada, distanciado de la polimetría propugnada por Lope, calza con la práctica poética de Gaspar Aguilar, la cual se inscribe dentro del contexto de la dramaturgia valenciana que «valoraba el verso octosílabo, y en particular la quintilla y la redondilla» (p. 17). Además de esta característica, la preponderancia casi absoluta del consonantismo $(96 \%)$, la alta cantidad de cadencias de autorrimas y cuasi-autorrimas y la ausencia de un correlato entre la segmentación dramática y la versificación, hace que el editor concluya que la autoría de La segunda comedia de Los agravios perdonados pertenece a Gaspar Aguilar y no a Luis Vélez de Guevara. Con esto, Peale propone la datación de la composición de la pieza entre 1601 y 1607, es decir, durante los años de la estadía en Madrid del ingenio valenciano. Por último, tras su minucioso análisis métrico, George Peale no deja de notar un hecho sustancial relativo a los principios poéticos del texto editado:

la poesía de La comedia segunda de Los agravios perdonados y, efectivamente, de todas las obras dramáticas de Gaspar Aguilar, relativiza algunos principios aceptados por la crítica actual, porque la voz y el medio métrico de su autor no se ajustan sino en parte a los cánones del Arte Nuevo (p. 24).

En cuanto a los criterios de la edición, Peale usa como texto base un manuscrito de sesenta hojas con letra del siglo XVII, el único testimonio conservado de la comedia que se encuentra en la Biblioteca Nacional de España. Un elemento que hay destacar de esta publicación es la adición pertinente y rigurosamente justificada de numerosos apartes y acotaciones ausentes en el manuscrito, que sin duda orientan la lectura de la obra y facilitan la reconstrucción de su puesta en escena. La anotación del texto, con el puntual señalamiento de las referencias léxicas, literarias, históricas y culturales, se complementa con un apartado final correspondiente a un índice de voces comentadas, de gran utilidad para el lector curioso. En suma, con la publicación de La comedia segunda de Los agravios perdonados, George Peale aporta una loable contribución al siempre creciente - pero nunca completocorpus de textos filológicamente editados del teatro del Siglo de Oro, de la mano de un conocedor especialista de las obras de Gaspar Aguilar y Luis Vélez de Guevara. 
